\title{
Short-Term Plasticity of Unitary Inhibitory-to-Inhibitory Synapses Depends on the Presynaptic Interneuron Subtype
}

\author{
Yunyong $\mathrm{Ma},{ }^{\star}$ Hang $\mathrm{Hu},{ }^{\star}$ and Ariel Agmon \\ Department of Neurobiology and Anatomy and the Sensory Neuroscience Research Center, West Virginia University School of Medicine, Morgantown, \\ West Virginia 26506-9303
}

Excitatory-to-inhibitory cortical synapses exhibit either short-term facilitation or depression, depending on the subtype identity of the postsynaptic interneuron, while the short-term plasticity (STP) of inhibitory-to-excitatory synapses depends on the presynaptic interneuron. However, the rules governing STP of inhibitory-to-inhibitory synapses have not yet been determined. We recorded 109 unitary connections made by the two major inhibitory interneuron subtypes in layer 4 of mouse somatosensory cortex, fast-spiking (FS) and somatostatin-containing ( $\mathrm{SOM}$ ) interneurons, on each other and on excitatory, regular-spiking (RS) neurons. In all pairs, we measured dynamic changes in the postsynaptic response to a $20 \mathrm{~Hz}$ train of presynaptic action potentials. In half of our dataset, we also measured kinetic properties of the unitary IPSC: latency, rise time, and decay time constant. We found a pronounced dependency of STP on the presynaptic, but not the postsynaptic, identity: FS interneurons made strongly depressing connections on FS, SOM, and RS targets, while in synapses made by SOM interneurons on FS and RS targets, weak early depression was followed by weak late facilitation. IPSC latency and rise time were also strongly dependent on the presynaptic interneuron subtype, being $1.5-2 \times$ slower in output synapses of SOM compared with FS interneurons. In contrast, the IPSC decay time constant depended only on the postsynaptic class, with $1.5 \times$ slower decay on excitatory compared with inhibitory targets. The properties of the inhibitory outputs of FS and SOM interneurons reciprocate the properties of their excitatory inputs and imply a dynamic spatiotemporal division of labor between these two major inhibitory subsystems.

\section{Introduction}

Chemical synaptic transmission has a remarkable capacity for up-modulations (facilitation) or down-modulations (depression) in the amplitude of the synaptic response, which persist over a wide range of time scales. This capacity, referred to as "synaptic plasticity," is thought to be the basis for the nervous system's ability to process and store information (Martin and Morris, 2002; Silva, 2003). Short-term plasticity (STP) refers to modulations that result from recent activity of the synapse over the previous tens to hundreds of milliseconds (Magleby, 1979; Zucker and Regehr, 2002). The STP amplitude and sign (depression or facilitation) vary between different synapses, raising the question: is STP a function of the presynaptic neuron, the postsynaptic neuron, or both? Note that this is not the same as asking whether the underlying mechanism resides presynaptically or

\footnotetext{
Received Oct. 2, 2011; revised Nov. 6, 2011; accepted Dec. 7, 2011.

Author contributions: Y.M. and A.A. designed research; Y.M. and H.H. performed research; Y.M., H.H., and A.A. analyzed data; A.A. wrote the paper.

This work was supported by NIH Grant NS050437 to A.A. and by NIH Grant RR015574 to the West Virginia University Sensory Neuroscience Research Center. We thank Cary Johnson and Qingyan Wang for excellent technical support. The authors of this manuscript are fully and solely responsible for its content.

*Y.M. and H.H. contributed equally to the work.

Correspondence should be addressed to Ariel Agmon, Department of Neurobiology and Anatomy and the Sensory Neuroscience Research Center, P.0. Box 9303, West Virginia University, Morgantown, WV 26506-9303. E-mail: aric.agmon@gmail.com.

Y. Ma's present address: Department of Neurology and Neurological Sciences, Stanford University, Stanford, CA 94305.

DOI:10.1523/JNEUROSCI.5007-11.2012

Copyright $\odot 2012$ the authors $\quad 0270-6474 / 12 / 320983-06 \$ 15.00 / 0$
}

postsynaptically. For example, STP can be a function of the postsynaptic neuron even if its cellular mechanism resides presynaptically, and vice versa, because the mechanism could be induced by transsynaptic signaling during synaptogenesis (Thomson and Deuchars, 1994; Reyes et al., 1998). Early dual recording experiments in neocortical brain slices revealed that unitary excitatory synapses on inhibitory interneurons $(\mathrm{E} \rightarrow \mathrm{I}$ synapses) can be either depressing or facilitating, depending on the subtype identity of the postsynaptic interneuron. Specifically, EPSPs on parvalbumin-containing fast-spiking (FS) interneurons, a major subtype characterized by multipolar morphology and a fast-spiking phenotype, usually exhibit depression, while EPSPs on somatostatin-containing (SOM) interneurons, which often have bitufted morphology and a burst-firing or lowthreshold spiking phenotype, exhibit facilitation (Thomson, 1997; Markram et al., 1998; Reyes et al., 1998). In contrast, STP of inhibitory-to-excitatory $(\mathrm{I} \rightarrow \mathrm{E})$ synapses depend on the identity of the presynaptic interneuron (but see Reyes et al., 1998; Gupta et al., 2000). For example, in cortical layer 4, FS $\rightarrow$ RS (regularspiking) synapses exhibit strong depression while $\mathrm{SOM} \rightarrow \mathrm{RS}$ synapses exhibit only slight depression or modest facilitation (Beierlein et al., 2003).

In addition to $\mathrm{I} \rightarrow \mathrm{E}$ synapses, inhibitory interneurons make $\mathrm{I} \rightarrow$ I synapses on other interneurons (Reyes et al., 1998; Gibson et al., 1999; Gupta et al., 2000; Thomson et al., 2002). However, a clear rule for predicting STP of I $\rightarrow$ I synapses has not yet emerged, and it is not known whether heterotypic I $\rightarrow$ I synapses (e.g., $\mathrm{FS} \rightarrow \mathrm{SOM}$ and $\mathrm{SOM} \rightarrow$ FS connections) follow the $\mathrm{E} \rightarrow \mathrm{I}$ 
rule of postsynaptic dependency, or the $\mathrm{I} \rightarrow \mathrm{E}$ rule of presynaptic dependency. Moreover, kinetic parameters of heterotypic $\mathrm{I} \rightarrow \mathrm{I}$ IPSCs have not been reported previously, and whether these parameters vary with the presynaptic or postsynaptic neuron is unknown. Here we show that STP and some kinetic parameters of $\mathrm{I} \rightarrow \mathrm{I}$ connections depend on the subtype of the presynaptic interneuron, but that the IPSC decay time constant varies with the class of the postsynaptic target.

\section{Materials and Methods}

Slice preparation. All animal-related procedures were approved by the West Virginia University Animal Care and Use Committee and adhered to U.S. Public Health Service regulations. Brain slices were prepared as previously described (Ma et al., 2006) from juvenile mice of either sex, postnatal days 15-23 (17.3 \pm 1.8 , mean \pm SD), mostly from the X94 mouse line (stock \#006334; The Jackson Laboratory), in which SOM neurons are identifiable by their GFP fluorescence. Some FS-FS and FS-RS pairs were recorded in slices from G42 mice (stock \#007677; The Jackson Laboratory), in which FS interneurons express GFP (Chattopadhyaya et al., 2004).

Electrophysiological recordings. Slices were superfused at a rate of $\sim 2 \mathrm{ml} / \mathrm{min}$ with oxygenated artificial CSF (ACSF) at $32^{\circ} \mathrm{C}$. ACSF contained the following (in $\mathrm{mM}$ ): $126 \mathrm{NaCl}, 3 \mathrm{KCl}, 1.25$ $\mathrm{NaH}_{2} \mathrm{PO}_{4}, 2 \mathrm{CaCl}_{2}, 1.3 \mathrm{MgSO}_{4}, 26 \mathrm{NaHCO}_{3}$, and 20 D-glucose. Dual whole-cell recording were done from adjacent layer 4 neurons in current- or voltage-clamp mode, using the Axoclamp 2B or Axopatch 200B amplifiers, respectively (Molecular Devices). Glass micropipettes (typically 5-8 $\mathrm{M} \Omega$ resistance for current-clamp, 3-4 $\mathrm{M} \Omega$ for voltage-clamp) were filled with the following (in $\mathrm{mm}$ ): $134 \mathrm{~K}$-gluconate, 3.5 $\mathrm{KCl}, 0.1 \mathrm{CaCl}_{2}$, 10 HEPES, 1.1 EGTA, $4 \mathrm{Mg}$ ATP, 10 phosphocreatine-Tris, and $2 \mathrm{mg} / \mathrm{ml}$ biocytin ( $\mathrm{pH} 7.25, \sim 290 \mathrm{mOsm}$ ). Immediately upon break-in, a standardized set of subthreshold and suprathreshold voltage responses to intracellular current injection were recorded and used post hoc to calculate intrinsic membrane parameters and verify the subtype identity of the neuron as SOM, FS, or RS (Ma et al., 2006; Tan et al., 2008; Hu et al., 2011). Single and trains of presynaptic action potentials were then elicited every $8-15 \mathrm{~s}$ using brief (2-4 ms) current pulses, and unitary inhibitory postsynaptic responses (uIPSC/Ps) were recorded while holding the postsynaptic neuron at $-50 \mathrm{mV}$. Records were filtered at $3 \mathrm{kHz}$ (current-clamp) or $2 \mathrm{kHz}$ (voltage-clamp) and digitized at $20 \mathrm{kHz}$.

Data analysis. For kinetic parameter measurements [latency, rise time, and decay time constant $(\tau)], 20-30$ uIPSCs were aligned on the peak of the presynaptic spike and averaged. Latency was defined as the interval between the peak of the presynaptic spike and $20 \%$ of the peak of the UIPSC; rise time was measured between $20-80 \%$ of the peak of the uIPSC; decay $\tau$ was measured by fitting a single exponential to the decay phase of the UIPSC. Dynamic (STP) parameters were measured from averaged $20 \mathrm{~Hz}$ trains of $8-10 \mathrm{uIPSC} / \mathrm{Ps}$ followed by a single response $500 \mathrm{~ms}$ later (recovery test) (Gupta et al., 2000). Paired-pulse ratio (PPR) was defined as the ratio of the second to first response; last-to-first ratio (LFR) as the ratio of the averaged seventh
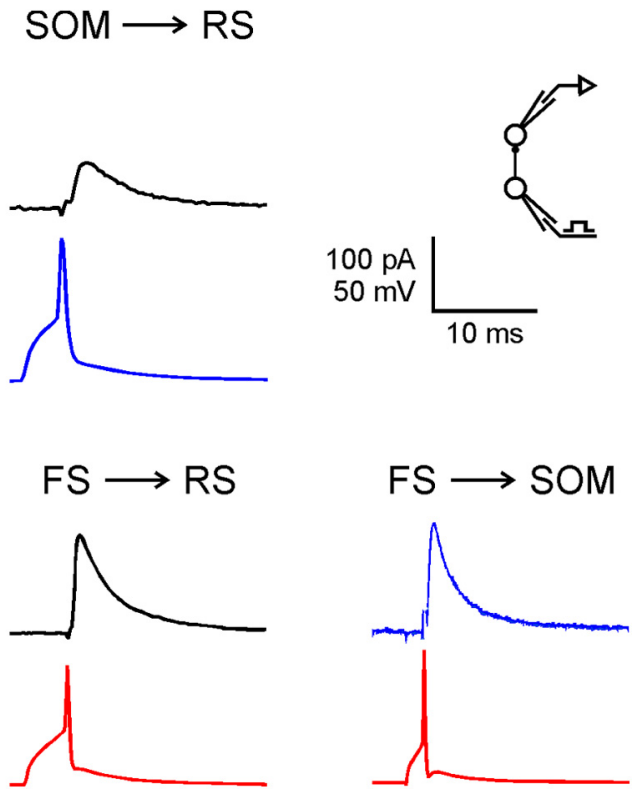

Figure 1. Averaged uIPSCs representing the five groups of inhibitory connections studied. In each panel, the postsynaptic current is shown above the simultaneously recorded presynaptic action potential. Holding potentials were $-50 \mathrm{mV}$. Traces are color coded by subtype (FS, red; SOM, blue; RS, black).
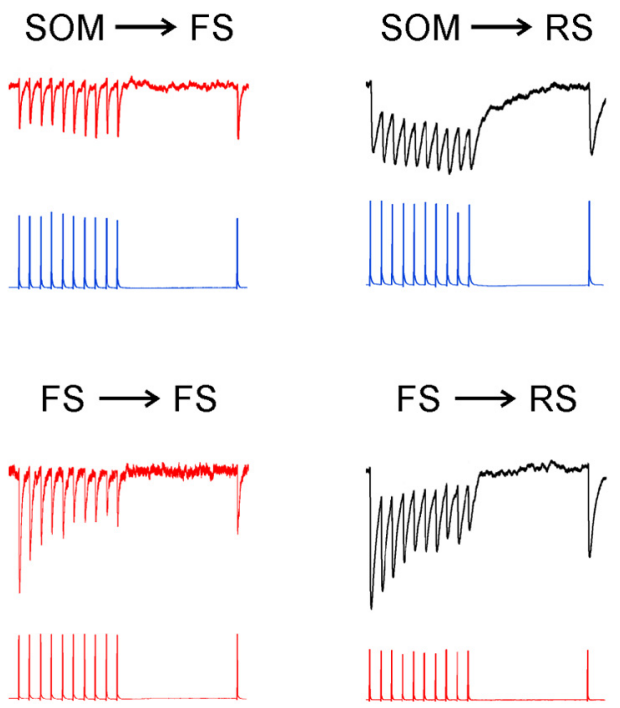
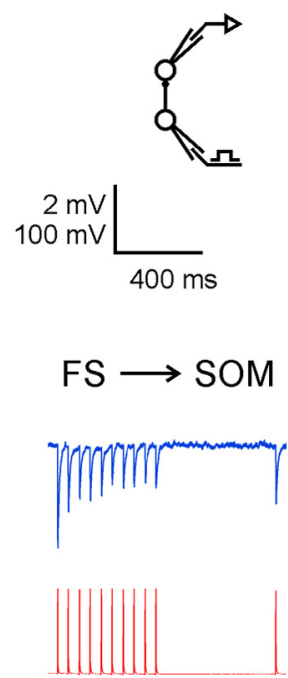

Figure 2. Averaged trains of uIPSPs elicited at $20 \mathrm{~Hz}$, representing the five groups of inhibitory connections studied. Traces are color coded by subtype (FS, red; SOM, blue; RS, black).

and eighth responses to the first response; and recovery test ratio (RTR) as the ratio of the recovery test to the first response. Minimal response amplitudes used for analysis were $20 \mathrm{pA}$ or $0.5 \mathrm{mV}$ for dynamic parameters and $25 \mathrm{pA}$ for kinetic parameters; this criterion excluded 10 connected pairs from analysis.

Statistics. Statistical significance $(p)$ values were determined by comparing the observed difference between means (two group comparisons) or the observed $F$ ratio (three group comparisons) to the distribution of values computed from 10,000 random permutations of the data. Computations were performed in MathCad.

\section{Results}

Using paired whole-cell recordings in brain slices of mouse somatosensory (barrel) cortex, we examined the properties of $\mathrm{I} \rightarrow \mathrm{I}$ synapses made by FS and SOM inhibitory interneurons and compared them to $\mathrm{I} \rightarrow \mathrm{E}$ synapses made by the same subtypes. Our 
Table 1. Average kinetic and dynamic properties of the five groups of connections

\begin{tabular}{|c|c|c|c|c|c|c|c|c|}
\hline & \multirow[b]{2}{*}{ ulPSC (pA) } & \multirow[b]{2}{*}{$\mathrm{ulPSP}(\mathrm{mV})$} & \multicolumn{3}{|l|}{ Dynamics } & \multicolumn{3}{|l|}{ Kinetics } \\
\hline & & & PPR & LFR & RTR & Latency & Rise time & Decay $\tau$ \\
\hline \multicolumn{9}{|l|}{ 1. $\mathrm{SOM} \rightarrow \mathrm{FS}$} \\
\hline$N$ & 21 & 16 & 37 & 37 & 37 & 21 & 21 & 21 \\
\hline Mean & 117.8 & 1.38 & 0.85 & 0.91 & 1.11 & 0.93 & 0.47 & 2.84 \\
\hline SEM & 13.7 & 0.22 & 0.02 & 0.03 & 0.03 & 0.03 & 0.01 & 0.17 \\
\hline \multicolumn{9}{|l|}{ 2. SOM $\rightarrow$ RS } \\
\hline$N$ & 11 & 7 & 18 & 18 & 18 & 9 & 9 & 10 \\
\hline Mean & 40.5 & 1.04 & 0.85 & 0.91 & 1.12 & 1.05 & 0.57 & 4.31 \\
\hline SEM & 5.1 & 0.18 & 0.03 & 0.04 & 0.03 & 0.04 & 0.02 & 0.37 \\
\hline \multicolumn{9}{|l|}{ 3. FS $\rightarrow \mathrm{SOM}$} \\
\hline$N$ & 5 & 10 & 15 & 15 & 15 & 4 & 4 & 4 \\
\hline Mean & 64.4 & 1.82 & 0.73 & 0.41 & 0.57 & 0.50 & 0.28 & 2.46 \\
\hline SEM & 24.0 & 0.33 & 0.02 & 0.02 & 0.03 & 0.04 & 0.02 & 0.25 \\
\hline \multicolumn{9}{|l|}{ 4. FS $\rightarrow \mathrm{FS}$} \\
\hline N & 10 & 16 & 26 & 26 & 26 & 10 & 10 & 10 \\
\hline Mean & 83.1 & 1.79 & 0.72 & 0.39 & 0.54 & 0.64 & 0.31 & 2.26 \\
\hline SEM & 16.7 & 0.19 & 0.02 & 0.02 & 0.02 & 0.04 & 0.01 & 0.20 \\
\hline \multicolumn{9}{|l|}{ 5. FS $\rightarrow \mathrm{RS}$} \\
\hline N & 8 & 5 & 13 & 13 & 12 & 6 & 6 & 6 \\
\hline Mean & 82.1 & 2.70 & 0.64 & 0.35 & 0.56 & 0.60 & 0.32 & 3.90 \\
\hline SEM & 32.1 & 0.68 & 0.03 & 0.02 & 0.02 & 0.02 & 0.01 & 0.24 \\
\hline 1 versus 2 & (different targets of SOM) & & $p=0.83$ & $p=0.96$ & $p=0.73$ & $p=0.03$ & $p<0.001$ & $p<0.001$ \\
\hline 3 versus 4 versus 5 & (different targets of FS) & & $p=0.03$ & $p=0.28$ & $p=0.49$ & $p=0.13$ & $p=0.41$ & $p<0.001$ \\
\hline 1,2 versus $3,4,5$ & (presynaptic SOM versus FS) & & $p<0.0001$ & $p<0.0001$ & $p<0.0001$ & $p<0.0001$ & $p<0.0001$ & $p=0.10$ \\
\hline 2,5 versus $1,3,4$ & (postsynaptic E versus I) & & $p=0.35$ & $p=0.55$ & $p=0.22$ & $p=0.30$ & $p=0.06$ & $p<0.0001$ \\
\hline
\end{tabular}

Bottom four rows are statistical test results.

dataset consisted of 98 synaptically connected pairs that yielded 109 inhibitory connections (eleven pairs were connected bidirectionally), falling into three $\mathrm{I} \rightarrow \mathrm{I}$ and two $\mathrm{I} \rightarrow \mathrm{E}$ groups. Connection probabilities for these five groups were 0.56 for $\mathrm{SOM} \rightarrow \mathrm{FS}$, 0.38 for $\mathrm{SOM} \rightarrow \mathrm{RS}, 0.61$ for $\mathrm{FS} \rightarrow \mathrm{SOM}, 0.48$ for $\mathrm{FS} \rightarrow \mathrm{FS}$, and 0.63 for $\mathrm{FS} \rightarrow \mathrm{RS}$. Rates of reciprocal connectivity were not significantly different from random (Fisher's exact test). Chemical $\mathrm{SOM} \rightarrow \mathrm{SOM}$ synapses were never observed (Gibson et al., 1999; $\mathrm{Hu}$ et al., 2011). In 54 of these connections, both neurons were recorded in current-clamp mode; in the remaining 55, the postsynaptic neuron was voltage-clamped. As previously reported, some of the FS-FS pairs were coupled electrically in addition to being connected chemically (Gibson et al., 1999; Galarreta and Hestrin, 2002); coupled and noncoupled FS-FS pairs were pooled.

We tested all connections by eliciting both single spikes and 20 $\mathrm{Hz}$ spike trains in the presynaptic interneuron; $20 \mathrm{~Hz}$ is within the range of firing frequencies of FS and SOM interneurons in response to visual stimulation in vivo (Ma et al., 2010). Representative averaged uIPSCs from the five groups of connections are shown in Figure 1; representative averaged UIPSP trains are shown in Figure 2. From averaged single uIPSCs, we measured three kinetic parameters: latency, rise time, and decay $\tau$. From averaged $20 \mathrm{~Hz}$ trains of uIPSC/Ps, we measured three dynamic STP parameters: PPR, LFR, and RTR (for definitions, see Materials and Methods, above). There were no significant differences in STP parameters between voltage-clamp and current-clamp data except for the RTR, which was $\sim 10-20 \%$ larger in voltageclamp data, but this was true for output synapses of both SOM and FS interneurons, so it did not affect the difference between the two groups. The six parameters are summarized in Table 1 by group, and represented graphically in Figure 3.

From Figure 3 and the $p$ values in Table 1, it is clear that the three dynamic parameters differed very significantly based on the presynaptic interneuron subtype, but were similar for different postsynaptic targets (Fig. 3, top; note vertically displaced but nearly horizontal parallel lines). Specifically, synapses made by FS interneurons depressed by $60 \%$ or more by the end of a $20 \mathrm{~Hz}, 8$ pulse train, and remained depressed $500 \mathrm{~ms}$ later; synapses made by SOM interneurons depressed by $\sim 10 \%$ during the train, but recovered and then facilitated by approximately the same amount, remaining facilitated $500 \mathrm{~ms}$ later. The first two kinetic parameters, uIPSC latency and rise time, also varied very significantly between presynaptic interneuron subtypes and were $>1.5 \times$ slower in connections made by SOM versus FS interneurons. In addition, when the presynaptic neuron was SOM, they depended to some degree on the postsynaptic neuron and were $\sim 20 \%$ slower on RS versus FS targets (Fig. 3, bottom left, bottom middle; note sloping blue lines). Finally, the uIPSC decay $\tau$ differed very significantly between excitatory and inhibitory postsynaptic targets, being $>1.5$-fold slower in the former (Fig. 3, bottom right; note strongly sloping blue and red lines), but was independent of either the presynaptic or postsynaptic interneuron subtype.

Previous studies showed an age-related increase in PPR of neocortical EPSPs (Reyes and Sakmann, 1999) and IPSPs (Takesian et al., 2010) during early postnatal development; we therefore tested for correlations between postnatal age and the measured synaptic parameters. The PPR increased only slightly within our age range (trend line rose by $\sim 0.1$ ), while the LFR and RTR remained essentially constant, as did latency and rise time. Of the six parameters, only the decay $\tau$ showed a significant developmentally related trend, decreasing by $\sim 1.5 \mathrm{~ms}$ within the age range used in our study $\left(r^{2}=0.09\right.$ and 0.26 for uIPSCs on excitatory and inhibitory neurons, respectively).

\section{Discussion}

The current report is, to our knowledge, the first systematic study of the kinetic and dynamic properties of synapses between neocortical FS and SOM interneurons, the two major interneuron subtypes in the neocortex. Our major finding was that the sign and amplitude of STP in these $\mathrm{I} \rightarrow \mathrm{I}$ synapses, like in $\mathrm{I} \rightarrow \mathrm{E}$ syn- 
apses (Gupta et al., 2000; Beierlein et al., 2003), depended on the subtype of the presynaptic interneuron. Specifically, STP was strongly depressing in synapses made by FS interneurons, and weakly depressing to weakly facilitating in output synapses of SOM interneurons, regardless of postsynaptic target class or subtype. Kinetic uIPSC parameters showed mixed dependencies: latency and rise time were strongly dependent on the presynaptic interneuron, being $>1.5 \times$ slower in synapses made by SOM versus FS interneurons, but within the former they were somewhat slower if the postsynaptic cell was excitatory. Finally, decay $\tau$ varied widely between excitatory and inhibitory targets, being $>1.5 \times$ slower in the former, but did not depend on the presynaptic or postsynaptic interneuron subtype. Our findings are at odds with a previous report (Reyes et al., 1998) of target-dependent STP of the output synapses of bitufted, putative SOM interneurons in upper cortical layers of postnatal day 14 rats. This discrepancy could reflect differences in species or age; alternatively, SOM interneurons in layers $2 / 3$ may differ from those in layer 4 in their STP properties, just as they differ in their intrinsic properties (Ma et al., 2006).

\section{Dynamics of unitary inhibitory synapses depend on the presynaptic interneuron}

Various mechanisms have been proposed to explain the differences in short-term plasticity between $\mathrm{E} \rightarrow \mathrm{I}$ synapses on FS and SOM interneurons, including P/Q- versus N-type calcium channels (Ali and Nelson, 2006), presynaptic calciumpermeable kainate receptors (Sun and Dobrunz, 2006), and a longer diffusional distance for presynaptic $\mathrm{Ca}^{2+}$ in $\mathrm{RS} \rightarrow \mathrm{SOM}$ synapses (Rozov et al., 2001). One can explain the presynaptic dependency of $\mathrm{I} \rightarrow \mathrm{E}$ and $\mathrm{I} \rightarrow \mathrm{I}$ dynamics by similar mechanisms. Indeed, differences in the subtypes of $\mathrm{Ca}^{2+}$ channels in presynaptic terminals have been implicated in a study of facilitating and depressing synapses made, respectively, by cholecystokinin (CCK)-positive and CCK-negative interneurons in the hippocampus (Ali, 2011).

\section{uIPSC kinetics depend on both presynaptic and postsynaptic neurons}

Like the STP of the inhibitory response, uIPSC rise-time and latency depended mostly on the subtype of the presynaptic interneuron and not on its target, with uIPSCs made by SOM interneurons having longer latencies and slower rise times compared with those made by FS interneurons, consistent with previous reports (Xiang et al., 2002; Koyanagi et al., 2010). The same mechanisms accounting for synaptic dynamics could be invoked to explain kinetic properties. For example, a relatively long distance between the presynaptic $\mathrm{Ca}^{2+}$ channel and the vesicle fusion site could result in a gradually increasing probability of release during high-frequency firing as $\mathrm{Ca}^{2+}$ accumulates, accounting for facilitation, and could also account for a longer latency between presynaptic spike and vesicle fusion, due to the slow rise of presynaptic $\left[\mathrm{Ca}^{2+}\right]$, and for a slower IPSC rise time, due to reduced release synchrony (Rozov et al., 2001).

Synapses made by SOM interneurons exhibited a secondary dependency on the class of the target neuron, with uIPSCs having slower rise times and latencies on excitatory versus inhibitory targets. The apparent slower kinetics of $\mathrm{SOM} \rightarrow \mathrm{RS}$ uIPSCs, as recorded in the soma, could be an outcome of the presumed dendritic location of these synapses (Maccaferri et al., 2000; Wang et al., 2004), which would be expected to result in electrotonic filtering of the synaptic current (Spruston et al., 1993).

In synapses made by both SOM and FS interneurons, uIPSC decay time constants depended only on the broad class (E or I) of the postsynaptic neuron, with the two types of I $\rightarrow$ E uIPSCs having slower decay $\tau$, compared with the three types of $\mathrm{I} \rightarrow \mathrm{I}$ connections. This is consistent with findings in hippocampus (Bartos et al., 2001; Patenaude et al., 2005). The slower decay of $\mathrm{SOM} \rightarrow \mathrm{RS}$ uIPSCs could again be attributable to the dendritic location of the synapse, but FS $\rightarrow$ RS synapses are presumed to be located proximally, so the slower decay of the FS $\rightarrow$ RS compared with $\mathrm{FS} \rightarrow \mathrm{FS}$ and $\mathrm{FS} \rightarrow \mathrm{SOM}$ uIPSCs points to a possible difference in the postsynaptic $\mathrm{GABA}_{\mathrm{A}}$ receptor properties between these synapses.

\section{Functional implications}

As previously noted (Beierlein et al., 2003), there is reciprocity in the properties of input and output synapses of the FS and SOM interneuron subtypes. Unitary excitatory inputs onto FS interneurons are fast-rising and fast-decaying (Geiger et al., 1997; Angulo et al., 1999), generate rapid and short EPSPs (Fricker and Miles, 2000), and thereby give rise to precisely timed postsynaptic spikes, allowing FS interneurons to function as coincident detectors (Galarreta and Hestrin, 2001). Similar properties are found in the output synapses of FS interneurons: both $\mathrm{FS} \rightarrow \mathrm{RS}$ and $\mathrm{FS} \rightarrow \mathrm{FS}$ uIPSCs have fast rise times (as confirmed in this study) and, as a result, FS cells can precisely entrain spikes in postsynaptic neurons and promote network oscillations (Cobb et al., 1995; Bartos et al., 2002). However, RS $\rightarrow$ FS inputs, while strong and reliable initially, are markedly depressed during prolonged activity; likewise, $\mathrm{FS} \rightarrow \mathrm{RS}$ synapses are depressed during ongoing activity (as confirmed in this study), albeit less than RS $\rightarrow$ FS synapses (Galarreta and Hestrin, 1998). Thus, the RS $\rightarrow \mathrm{FS} \rightarrow \mathrm{RS}$ circuit of feedback inhibition, as well as the thalamus $\rightarrow$ FS $\rightarrow$ RS circuit of feedforward inhibition (Porter et al., 2001; Gabernet et al., 2005; Cruikshank et al., 2007), are optimized to transmit transient information about novel stimuli, rather than sustained information as expected, for example, during ongoing sensory exploration. Here we extended these principles to $\mathrm{FS} \rightarrow$ SOM synapses, which are just as rapid in latency and rise time as the other FS outputs and show identical frequency- 
dependent depression. Thus, SOM interneurons will be powerfully but transiently inhibited by FS interneurons in response to novel stimuli, but this inhibition will fade out during ongoing sensory activity.

In contrast to synapses on and by FS interneurons, synapses between excitatory neurons and SOM interneurons have slower kinetics in both directions. This slow kinetics was extended in the present study to SOM $\rightarrow$ FS synapses. Thus, EPSPs elicited in SOM interneurons and IPSPs elicited by SOM interneurons will be less temporally precise than those of FS interneurons. However, due to the strong facilitation of RS $\rightarrow \mathrm{SOM}$ responses and to the slight facilitation of $\mathrm{SOM} \rightarrow \mathrm{RS}$ responses, the RS $\rightarrow \mathrm{SOM} \rightarrow \mathrm{RS}$ circuit can generate powerful, frequencydependent feedback inhibition (Kapfer et al., 2007; Silberberg and Markram, 2007). Moreover, during active cortical states, SOM interneurons are likely to be strongly excited by ascending modulatory inputs (Fanselow et al., 2008) and by incoming inputs from the thalamus (Tan et al., 2008), and their capacity to generate sustained, high-frequency inhibitory output will allow them to suppress activity not only in neighboring excitatory neurons, but also, as the current findings imply, in FS interneurons. Thus, the two systems of interneurons are perfectly optimized to play complementary roles, with a spatiotemporal division of labor between them: FS interneurons provide powerful somatic inhibition to excitatory neurons, but this inhibition will be greatly reduced during sustained sensory input due to the depression of their excitatory inputs, the depression of their inhibitory outputs, and (as shown here) the slightly facilitating inhibition they receive from SOM interneurons. The latter will then take over and replace the transient somatic inhibition with a delayed but sustained dendritic-targeted inhibition that may gate or sculpt late excitatory inputs arriving onto dendritic spines (Tan et al., 2008; Ma et al., 2010).

\section{References}

Ali AB (2011) CB1 modulation of temporally distinct synaptic facilitation among local circuit interneurons mediated by $\mathrm{N}$-type calcium channels in CA1. J Neurophysiol 105:1051-1062.

Ali AB, Nelson C (2006) Distinct Ca2 + channels mediate transmitter release at excitatory synapses displaying different dynamic properties in rat neocortex. Cereb Cortex 16:386-393.

Angulo MC, Rossier J, Audinat E (1999) Postsynaptic glutamate receptors and integrative properties of fast-spiking interneurons in the rat neocortex. J Neurophysiol 82:1295-1302.

Bartos M, Vida I, Frotscher M, Geiger JR, Jonas P (2001) Rapid signaling at inhibitory synapses in a dentate gyrus interneuron network. J Neurosci 21:2687-2698.

Bartos M, Vida I, Frotscher M, Meyer A, Monyer H, Geiger JR, Jonas P (2002) Fast synaptic inhibition promotes synchronized gamma oscillations in hippocampal interneuron networks. Proc Natl Acad Sci U S A 99:13222-13227.

Beierlein M, Gibson JR, Connors BW (2003) Two dynamically distinct inhibitory networks in layer 4 of the neocortex. J Neurophysiol 90:2987-3000.

Chattopadhyaya B, Di Cristo G, Higashiyama H, Knott GW, Kuhlman SJ, Welker E, Huang ZJ (2004) Experience and activity-dependent maturation of perisomatic GABAergic innervation in primary visual cortex during a postnatal critical period. J Neurosci 24:9598-9611.

Cobb SR, Buhl EH, Halasy K, Paulsen O, Somogyi P (1995) Synchronization of neuronal activity in hippocampus by individual GABAergic interneurons. Nature 378:75-78.

Cruikshank SJ, Lewis TJ, Connors BW (2007) Synaptic basis for intense thalamocortical activation of feedforward inhibitory cells in neocortex. Nat Neurosci 10:462-468.

Fanselow EE, Richardson KA, Connors BW (2008) Selective, state-dependent activation of somatostatin-expressing inhibitory interneurons in mouse neocortex. J Neurophysiol 100:2640-2652.
Fricker D, Miles R (2000) EPSP amplification and the precision of spike timing in hippocampal neurons. Neuron 28:559-569.

Gabernet L, Jadhav SP, Feldman DE, Carandini M, Scanziani M (2005) Somatosensory integration controlled by dynamic thalamocortical feedforward inhibition. Neuron 48:315-327.

Galarreta M, Hestrin S (1998) Frequency-dependent synaptic depression and the balance of excitation and inhibition in the neocortex. Nat Neurosci 1:587-594.

Galarreta M, Hestrin S (2001) Spike transmission and synchrony detection in networks of GABAergic interneurons. Science 292:2295-2299.

Galarreta M, Hestrin S (2002) Electrical and chemical synapses among parvalbumin fast-spiking GABAergic interneurons in adult mouse neocortex. Proc Natl Acad Sci U S A 99:12438-12443.

Geiger JR, Lübke J, Roth A, Frotscher M, Jonas P (1997) Submillisecond AMPA receptor-mediated signaling at a principal neuron-interneuron synapse. Neuron 18:1009-1023.

Gibson JR, Beierlein M, Connors BW (1999) Two networks of electrically coupled inhibitory neurons in neocortex. Nature 402:75-79.

Gupta A, Wang Y, Markram H (2000) Organizing principles for a diversity of GABAergic interneurons and synapses in the neocortex. Science 287:273-278.

Hu H, Ma Y, Agmon A (2011) Submillisecond firing synchrony between different subtypes of cortical interneurons connected chemically but not electrically. J Neurosci 31:3351-3361.

Kapfer C, Glickfeld LL, Atallah BV, Scanziani M (2007) Supralinear increase of recurrent inhibition during sparse activity in the somatosensory cortex. Nat Neurosci 10:743-753.

Koyanagi Y, Yamamoto K, Oi Y, Koshikawa N, Kobayashi M (2010) Presynaptic interneuron subtype- and age-dependent modulation of GABAergic synaptic transmission by beta-adrenoceptors in rat insular cortex. J Neurophysiol 103:2876-2888.

Ma WP, Liu BH, Li YT, Huang ZJ, Zhang LI, Tao HW (2010) Visual representations by cortical somatostatin inhibitory neurons-selective but with weak and delayed responses. J Neurosci 30:14371-14379.

Ma Y, Hu H, Berrebi AS, Mathers PH, Agmon A (2006) Distinct subtypes of somatostatin-containing neocortical interneurons revealed in transgenic mice. J Neurosci 26:5069-5082.

Maccaferri G, Roberts JD, Szucs P, Cottingham CA, Somogyi P (2000) Cell surface domain specific postsynaptic currents evoked by identified GABAergic neurones in rat hippocampus in vitro. J Physiol 524:91-116.

Magleby KL (1979) Facilitation, augmentation, and potentiation of transmitter release. Prog Brain Res 49:175-182.

Markram H, Wang Y, Tsodyks M (1998) Differential signaling via the same axon of neocortical pyramidal neurons. Proc Natl Acad Sci U S A 95:5323-5328.

Martin SJ, Morris RG (2002) New life in an old idea: the synaptic plasticity and memory hypothesis revisited. Hippocampus 12:609-636.

Patenaude C, Massicotte G, Lacaille JC (2005) Cell-type specific GABA synaptic transmission and activity-dependent plasticity in rat hippocampal stratum radiatum interneurons. Eur J Neurosci 22:179-188.

Porter JT, Johnson CK, Agmon A (2001) Diverse types of interneurons generate thalamus-evoked feedforward inhibition in the mouse barrel cortex. J Neurosci 21:2699-2710.

Reyes A, Sakmann B (1999) Developmental switch in the short-term modification of unitary EPSPs evoked in layer $2 / 3$ and layer 5 pyramidal neurons of rat neocortex. J Neurosci 19:3827-3835.

Reyes A, Lujan R, Rozov A, Burnashev N, Somogyi P, Sakmann B (1998) Target-cell-specific facilitation and depression in neocortical circuits. Nat Neurosci 1:279-285.

Rozov A, Burnashev N, Sakmann B, Neher E (2001) Transmitter release modulation by intracellular Ca2 + buffers in facilitating and depressing nerve terminals of pyramidal cells in layer $2 / 3$ of the rat neocortex indicates a target cell-specific difference in presynaptic calcium dynamics. J Physiol 531:807-826.

Silberberg G, Markram H (2007) Disynaptic inhibition between neocortical pyramidal cells mediated by Martinotti cells. Neuron 53:735-746.

Silva AJ (2003) Molecular and cellular cognitive studies of the role of synaptic plasticity in memory. J Neurobiol 54:224-237.

Spruston N, Jaffe DB, Williams SH, Johnston D (1993) Voltage- and spaceclamp errors associated with the measurement of electrotonically remote synaptic events. J Neurophysiol 70:781-802.

Sun HY, Dobrunz LE (2006) Presynaptic kainate receptor activation is a 
novel mechanism for target cell-specific short-term facilitation at Schaffer collateral synapses. J Neurosci 26:10796-10807.

Takesian AE, Kotak VC, Sanes DH (2010) Presynaptic GABA(B) receptors regulate experience-dependent development of inhibitory short-term plasticity. J Neurosci 30:2716-2727.

Tan Z, Hu H, Huang ZJ, Agmon A (2008) Robust but delayed thalamocortical activation of dendritic-targeting inhibitory interneurons. Proc Natl Acad Sci U S A 105:2187-2192.

Thomson AM (1997) Activity-dependent properties of synaptic transmission at two classes of connections made by rat neocortical pyramidal axons in vitro. J Physiol 502:131-147.

Thomson AM, Deuchars J (1994) Temporal and spatial properties of local circuits in neocortex. Trends Neurosci 17:119-126.
Thomson AM, West DC, Wang Y, Bannister AP (2002) Synaptic connections and small circuits involving excitatory and inhibitory neurons in layers $2-5$ of adult rat and cat neocortex: triple intracellular recordings and biocytin labelling in vitro. Cereb Cortex 12:936-953.

Wang Y, Toledo-Rodriguez M, Gupta A, Wu C, Silberberg G, Luo J, Markram H (2004) Anatomical, physiological and molecular properties of Martinotti cells in the somatosensory cortex of the juvenile rat. J Physiol 561:65-90.

Xiang Z, Huguenard JR, Prince DA (2002) Synaptic inhibition of pyramidal cells evoked by different interneuronal subtypes in layer $\mathrm{v}$ of rat visual cortex. J Neurophysiol 88:740-750.

Zucker RS, Regehr WG (2002) Short-term synaptic plasticity. Annu Rev Physiol 64:355-405. 